\title{
Subjective and psychological well-being among elderly participants of a University of the Third Age
}

\author{
Meire Cachioni' \\ Lais Lopes Delfino \\ Mônica Sanches Yassuda? \\ Samila Sathler Tavares Batistoni' \\ Ruth Caldeira de Melo' \\ Marisa Accioly Rodrigues da Costa Domingues ${ }^{1}$
}

\section{Abstract}

Objective: The present study aimed to analyze the distribution of measures of subjective and psychological well-being according to demographic criteria and length of participation in the program. Method: A cross sectional study using the following instruments was carried out: a sociodemographic questionnaire (age, gender, education, length of participation in University of the Third Age (U3A) and similar programs located in the city of São Paulo, Brazil; an Overall Life Satisfaction Scale; a Life Satisfaction Scale that contemplated four domains: health, physical capacity, mental capacity and social involvement; a Positive/ Negative Affect Scale; and a Personal Development Scale. The data were analyzed by the chi-squared test (for comparison of categorical variables), the Mann-Whitney and the Kruskal-Wallis U tests (for comparison of continuous variables). Results: Age and gender were the main factors that were significantly associated with overall life satisfaction, life satisfaction in specific domains, and morale. Higher education was associated with psychological adjustment. Conclusion: Participating in a U3A contributes to high levels of subjective and psychological well-being. Elderly individuals of more advanced ages and men had higher rates of satisfaction with life and positive feelings. The elderly can assess their development trajectory, their commitment to society and consider their efforts in pursuing an ideal of personal excellence.
Keywords: Subjective well-being. Psychological well-being. Elderly. Third Age Universities.

\footnotetext{
Universidade de São Paulo, Escola de Artes, Ciências e Humanidades. São Paulo, SP, Brasil.

2 Universidade Estadual de Campinas, Faculdade de Ciências Medicas, Programa de Pós Graduação em Gerontologia. Campinas, SP, Brasil.
} 


\section{INTRODUCTION}

The early 1960s saw major ideological changes in the field of gerontology. Old age and aging were no longer synonymous with disease, inactivity, and a general contraction in development. Since this time, gerontology has also investigated the positive aspects of old age, based on the view that it is possible to maintain well-being and quality of life even at advanced ages ${ }^{1}$. It was in this context that the term successful old age emerged, which includes among its several associated concepts those related to psychological well-being - positive mental health, which includes self-acceptance, mastery over one's environment, positive relationships with others, purpose, personal growth and autonomy ${ }^{2}-$ and to subjective well-being - general satisfaction with life and specific domains of functioning, such as health and social relationships, activity, social integration, sense of control, and sense of meaning of existence ${ }^{3}$.

The study of subjective well-being (SWB) seeks to understand people's assessment of their lives and has flourished with the growing recognition of the importance of subjectivity in assessing what makes life good and desirable. According to Diener and Louis $^{4}$, the indicators of SWB are satisfaction with life, positive and negative emotions. Emotions refer to the evaluation of SWB by affective criteria and are relatively less stable than satisfaction. The satisfaction with life dimension is the cognitive judgment of a specific domain in a person's life; an assessment of life according to one's own criteria. The judgment of satisfaction depends on a comparison between the individual's life circumstances and a standard chosen by the individual themselves ${ }^{5}$.

In the late 1980s, the significant amount of research on SWB, mainly by scholars from various fields of psychology, resulted in a crisis in defining the concept and a subdivision into subjective wellbeing and psychological well-being. In this same period, the North American psychologist Carol Ryff presented critical studies on the construct in the field of psychology. For this author, the perspective of well-being that translates to happiness and that which translates to personal excellence belong to different domains and must be analyzed based on different philosophical perspectives ${ }^{2,6}$.
According to $\mathrm{Ryff}^{6}$, an alternative and multidimensional model of psychological wellbeing (PWB), derived from theoretical and empirical discussions, encompasses six components: a) the meaning, purpose and direction people give to their lives; b) living according to their own personal convictions (autonomy); c) using their personal talents and their potential (personal growth); d) managing life situations (mastery over one's environment); e) maintaining deep and meaningful ties with others (positive relationships), and $\mathrm{f}$ ) self-knowledge, including awareness of personal limitations (self-acceptance).

The last few decades have witnessed major advances in the psychology of aging and intriguing discoveries regarding the well-being of individuals experiencing the final stage of life. Unpublished findings based on the perspective of lifespan (development throughout life) have generated new insights into the dynamics of well-being throughout life and on the factors that influence its maintenance or decline in old age. One of the most interesting findings was synthetically denominated in the 1990s as the "well-being paradox"7. This paradox brings together data showing that in old age SWB and the sense of maturity, or PWB, do not seem to decline despite the challenges and losses associated with age, and gains or increases in these indicators can be maintained ${ }^{8,9}$.

Data from the English Longitudinal Study of Ageing (ELSA) show that the elderly have higher levels of SWB than middle-aged adults. Life satisfaction is greatest in older groups especially when controlled for marital status and health. The authors conclude that these results are probably due to the adaptive nature of the SWB assessment measures, showing that even in the face of declining health, the elderly become more satisfied and happier with their situation than when they were younger ${ }^{10}$.

In old age, successful adaptation is linked to the balance between positive and negative affects, the selection of positive targets for affective and cognitive investment, the reduction of the intensity and variability of positive and negative emotional experiences, and a greater ability to experience more complex emotional experiences, to name and understand one's own emotions and the emotions of 
others, and to select social partners who represent an opportunity for emotional comfort (rather than information and status, which are typical themes of youth and adult life) ${ }^{11}$.

It is known that for the elderly, social contacts are motivated by events that provide well-being and meaningful social interactions which offer emotional support. Regularly maintained social contacts are those that possess greater significance as mediators of social support. In this perspective, the promotion of educational programs aimed at this age segment stands out. Such programs have an important role to play in the establishment of SWB for the elderly, since they can provide physical and mental activities, meaning and satisfaction with existence, both through the commitment and social responsibility implicit within them, and the opportunity to acquire and update knowledge and maintain a social life ${ }^{12}$.

In view of results previously published in literature, the present study aimed to verify indicators of subjective well-being and psychological well-being among elderly students attending the Universidade Aberta à Terceira Idade da Escola de Artes, Ciências e Humanidades (the Open University of the Third Age of the School of Arts, Sciences and Humanities) (UnATI EACH). The emphasis on well-being was aimed at describing the sample of elderly people according to sociodemographic criteria (age, gender, schooling) and time of participation in the UnATI $\mathrm{EACH}$ and other programs of this type.

\section{METHOD}

A cross-sectional study was performed. All the students enrolled in the UnATI EACH who could read and write were included, while the elderly with cognitive deficits suggestive of dementia and/or those with severe hearing or vision deficits, making communication and comprehension difficult, were excluded. The total number of students enrolled was 307, and when the inclusion and exclusion criteria were applied, the sample corresponded to 265 elderly people.

After public disclosure of the approval of the research project, the stages of the study were defined by six professors from the Bachelor's Degree in Gerontology of the EACH who established the research protocol, with one senior individual responsible for the entire process, from the creation of the research plan to the implementation of the entire schedule established by the partnership agreement. These six professors trained 20 students who agreed to act as research assistants.

Of these 20 research assistants, three students from the previous semester with the most experience were appointed as tutors of the others.

Instruments validated for the Brazilian elderly population were used, selecting the psychosocial variables of interest related to SWB and PWB:

\section{Sociodemographic data}

a) The independent variables age, gender and schooling; B) The time of participation in UnATI EACH; C) Participation in other Universities for the Third Age (U3A) or Social Centers.

\section{SWB Measures}

a) Scale for the measurement of Overall Satisfaction with Life: single item scale that asks for the evaluation of this condition on a scale of 1 to 10 , presented graphically ( $1=$ the worst life and $10=$ the best life); b) instrument for the measurement of Satisfaction with Life based on three domains: health and physical capacity, mental capacity and social involvement. Assessment is based on a fivepoint scale ranging from very unsatisfied to very satisfied; c) Positive and Negative Affect Schedule (PANAS): on a scale ranging from 1 (not at all) to 5 (very much), the subject is asked to evaluate their positive mood, composed of six expressions (happy, cheerful, excited, well, satisfied, contented) and their negative mood, indicated by eight expressions (irritated, demotivated, distressed, depressed, upset, nervous, sad, discouraged).

\section{Measures of PWB}

The Personal Development Scale (PDS), originally, contained 18 items corresponding to the six domains of PWB, as described by Ryff²: 
positive relations with others, personal growth, self-acceptance, autonomy, purpose in life and environmental mastery, and 12 items corresponding to three domains of generability - create, maintain and offer. Each item is rated by a five-point scale (1-very little, 2-little, 3-fair, 4-much, 5-very much). A methodological study of the instrument revealed a factorial structure containing five factors composed of 25 items, which explained $54.04 \%$ of total variability. These factors were denominated: self-realization, personal growth and psychological adjustment (Factor 1); Productivity (Factor 2); Care (Factor 3); Concern for the next generations (Factor 4) and Commitment to others (Factor 5). Analysis of the internal reliability of the scale as a whole and of each of the factors resulted in satisfactory scores for the total scale $(\alpha=0.90)$ and for Factors $1(\alpha=0.89)$, $2(\alpha=0.72), 3(\alpha=0.67), 4(\alpha=0.68)$ and $5(\alpha=0.64)$.

The chi-square test was used to compare the categorical variables, and when there were three categories or more to be analyzed, the chi-square test for multiple samples was used. The KolmogorovSmirnov test identified the absence of normal distribution of the continuous variables which therefore required non-parametric tests. Therefore, the Mann-Whitney and Kruskall-Wallis U-tests, respectively, were used to compare the continuous variables between two or three groups. In the Kruskal-Wallis test, the multiple comparison test (Multiple Comparisons z' values) was used when a $p$-value $<0.05$ was obtained.

The level of significance adopted for the statistical tests was $5 \%$, resulting in a $p$-value $<0.05$.

The research plan was approved by the Ethics Research Committee of the Instituto de Psicologia of the Universidade de São Paulo (the Psychology Institute of the University of São Paulo), under approval number 2010.043. The subjects agreed to participate by signing a Free and Informed Consent
Form. The present study complied with Resolution $n^{\circ}$ 196/96 on Regulatory Directives and Guidelines on Research involving Human Beings.

\section{RESULTS}

Table 1 shows that men scored higher than women in the health (mean $=3.90, \operatorname{sd} \pm 0.72)$ and mental (mean $=4.05$; sd \pm 0.77$)$ domains of the Domain Related Satisfaction Scale. They also presented an overall positive result in terms of Affect (mean=4.16; $\operatorname{sd} \pm 0.52)$.

Table 2 reveals that there were statistically significant differences when the elderly of different age groups were compared: elderly persons aged equal to or greater than 70 years scored higher in the Overall Satisfaction with Life Scale (mean=73.57; sd \pm 3.94$)$ than the elderly aged 60 to 64 years. -

The results show that, with the exception of educational level, the elderly were statistically the same in relation to the other socio-demographic variables and well-being, as shown in Table 3.

Elderly persons with different times of participation at the UnATI EACH were statistically equal in relation to the other socio-demographic variables and well-being, as shown in Table 4.

In order to analyze the impact of participation time on the subjective and psychological sense of wellbeing among UnATI EACH participants, the elderly were separated into two distinct groups: students with a participation time equal to or greater than one semester were enrolled in the Veterans group, while those who had never participated in the activities offered by UnATI EACH were described as First-years. Elderly persons with different participation times were statistically different, as can be seen in Table 5 . 
Table 1. Sociodemographic variables and well-being among male and female elderly persons. São Paulo, UnATI EACH, 2010.

\begin{tabular}{|c|c|c|c|}
\hline \multirow{3}{*}{ Variable } & \multicolumn{2}{|c|}{ Gender } & \multirow[b]{3}{*}{$p$-value* } \\
\hline & Male & Female & \\
\hline & $\operatorname{Mean}( \pm \mathrm{sd})$ & $\operatorname{Mean}( \pm \mathrm{sd})$ & \\
\hline Age & $67.22( \pm 5.61)$ & $66.97( \pm 5.43)$ & 0.759 \\
\hline Schooling & $10.88( \pm 4.89)$ & $9.69( \pm 4.56)$ & $0.040^{*}$ \\
\hline \multicolumn{4}{|l|}{ Time of Participation } \\
\hline UnATI EACH-USP & $1.89( \pm 2.03)$ & $2.11( \pm 2.18)$ & 0.464 \\
\hline Other U3A or Social Centers & $1.17( \pm 3.01)$ & $3.19( \pm 6.18)$ & $0.002^{*}$ \\
\hline \multicolumn{4}{|c|}{ Overall Satisfaction with Life Scale } \\
\hline OSL/Total & $8.17( \pm 1.47)$ & $8.29 \pm(1.53)$ & 0.408 \\
\hline \multicolumn{4}{|c|}{ Domain Related Satisfaction Scale } \\
\hline Health & $3.90( \pm 0.72)$ & $3.74( \pm 0.67)$ & $0.044^{*}$ \\
\hline Physical Capacity & $3.84( \pm 0.71)$ & $3.86( \pm 0.66)$ & 0.912 \\
\hline Mental Capacity & $4.05( \pm 0.77)$ & $3.84( \pm 0.67)$ & $0.011 *$ \\
\hline Social Involvement & $3.80( \pm 0.83)$ & $3.92( \pm 0.78)$ & $0.151^{*}$ \\
\hline DRS/ Total & $3.91( \pm 0.61)$ & $3.85( \pm 0.48)$ & 0.294 \\
\hline \multicolumn{4}{|l|}{ Affect Schedule } \\
\hline Positive (PA) & $3.88( \pm 0.53)$ & $3.76( \pm 0.58)$ & 0.083 \\
\hline Negative (NA) & $1.64( \pm 0.66)$ & $1.80( \pm 0.69)$ & 0.066 \\
\hline A/Total & $4.16( \pm 0.52)$ & $4.02( \pm 0.58)$ & $0.041 *$ \\
\hline \multicolumn{4}{|l|}{ Personal Development Scale } \\
\hline Factor 1 & $4.21( \pm 0.42)$ & $4.27( \pm 0.46)$ & 0.183 \\
\hline Factor 2 & $3.60( \pm 0.68)$ & $3.66( \pm 0.71)$ & 0.468 \\
\hline Factor 3 & $3.97( \pm 0.61)$ & $3.96( \pm 0.59)$ & 0.904 \\
\hline Factor 4 & $3.68( \pm 0.92)$ & $3.79( \pm 0.89)$ & 0.331 \\
\hline Factor 5 & $4.03( \pm 0.76)$ & $3.90( \pm 0.78)$ & 0.206 \\
\hline PDS/Total & $3.99( \pm 0.37)$ & $4.04( \pm 0.42)$ & 0.278 \\
\hline
\end{tabular}

*p-value related to chi-square test.

Table 2. Sociodemographic variables and well-being among elderly persons of different age ranges. São Paulo, UnATI EACH, 2010.

\begin{tabular}{|c|c|c|c|c|}
\hline \multirow{3}{*}{ Variable } & \multicolumn{3}{|c|}{ Age Range } & \multirow[b]{3}{*}{$p$-value* } \\
\hline & 60 to 64 years & 65 to 69 years & 70 years or more & \\
\hline & Mean $( \pm$ sd $)$ & Mean $( \pm$ sd $)$ & Mean $( \pm$ sd $)$ & \\
\hline Gender (Fem. \%) & $71.30 \%$ & $62.32 \%$ & $70.45 \%$ & $0.413^{*}$ \\
\hline Age & $61.98( \pm 1.43)^{\mathrm{b} . c}$ & $66.67( \pm 1.28)^{\mathrm{c}}$ & $73.57( \pm 3.49)$ & $<0.001$ \\
\hline Schooling & $10.26( \pm 4.89)$ & $10.75( \pm 4.47)$ & $9.30( \pm 4.55)$ & 01305 \\
\hline \multicolumn{5}{|l|}{ Time of Participation } \\
\hline UnATI EACH-USP & $1.78( \pm 1.99)$ & $2.17( \pm 2.27)$ & $2.26( \pm 2.19)$ & 0.228 \\
\hline Other U3A or Social Centers & $1.70( \pm 4.36)$ & $3.12( \pm 5.56)$ & $3.16( \pm 6.45)$ & 0.498 \\
\hline \multicolumn{5}{|c|}{ Overall Satisfaction with Life Scale } \\
\hline OSL/Total & $7.92( \pm 1.55)^{\mathrm{c}}$ & $8.41( \pm 1.35)$ & $8.55( \pm 1.51)$ & 0.009 \\
\hline
\end{tabular}


Continued from Table 2

\begin{tabular}{|c|c|c|c|c|}
\hline \multirow{3}{*}{ Variable } & \multicolumn{3}{|c|}{ Age Range } & \multirow[b]{3}{*}{$p$-value* } \\
\hline & 60 to 64 years & 65 to 69 years & 70 years or more & \\
\hline & Mean $( \pm$ sd) & Mean $( \pm$ sd) & Mean $( \pm$ sd) & \\
\hline \multicolumn{5}{|c|}{ Domain Related Satisfaction Scale } \\
\hline Health & $3.65( \pm 0.69)^{\mathrm{b}}$ & $3.92( \pm 0.73)$ & $3.86( \pm 0.64)$ & 0.025 \\
\hline Physical Capacity & $3.81( \pm 0.58)^{\mathrm{b}}$ & $4.04( \pm 0.74)^{\mathrm{c}}$ & $3.77( \pm 0.71)$ & 0.013 \\
\hline Mental Capacity & $3.83( \pm 0.69)$ & $4.04( \pm 0.77)$ & $3.89( \pm 0.67)$ & 0.140 \\
\hline Social Involvement & $3.86( \pm 0.75)$ & $3.86( \pm 0.93)$ & $3.93( \pm 0.75)$ & 0.823 \\
\hline DRS/Total & $3.80( \pm 0.48)^{\mathrm{b}}$ & $3.98( \pm 0.60)$ & $3.88( \pm 0.50)$ & 0.030 \\
\hline \multicolumn{5}{|l|}{ Affect Schedule } \\
\hline Positive (PA) & $3.68( \pm 0.64)^{\mathrm{b}}$ & $3.91( \pm 0.51)$ & $3.86( \pm 0.51)$ & 0.018 \\
\hline Negative (PN) & $1.95( \pm 0.78)$ & $1.67( \pm 0.55)^{\mathrm{c}}$ & $1.57( \pm 0.59)$ & 0.001 \\
\hline A/Total (PA-PN) & $3.91( \pm 0.64)^{\text {b.c }}$ & $4.15( \pm 0.46)$ & $4.19( \pm 0.49)$ & $<0.001$ \\
\hline \multicolumn{5}{|c|}{ Personal Development Scale } \\
\hline Factor 1 & $4.22( \pm 0.43)$ & $4.32( \pm 0.43)$ & $4.24( \pm 0.47)$ & 0.424 \\
\hline Factor 2 & $3.64( \pm 0.68)$ & $3.68( \pm 0.68)$ & $3.61( \pm 0.74)$ & 0.862 \\
\hline Factor 3 & $3.91( \pm 0.55)$ & $4.08( \pm 0.60)$ & $3.93( \pm 0.64)$ & 0.106 \\
\hline Factor 4 & $3.75( \pm 0.96)$ & $3.79( \pm 0.87)$ & $3.73( \pm 0.86)$ & 0.902 \\
\hline Factor 5 & $3.91( \pm 0.76)$ & $4.01( \pm 0.77)$ & $3.91( \pm 0.80)$ & 0.668 \\
\hline EDEP/Total & $4.00( \pm 0.39)$ & $4.09( \pm 0.39)$ & $4.00( \pm 0.42)$ & 0.364 \\
\hline
\end{tabular}

Table 3. Sociodemographic variables and well-being among elderly persons with different degrees of schooling. São Paulo, UnATI EACH, 2010.

\begin{tabular}{|c|c|c|c|c|c|}
\hline \multirow{3}{*}{ Variable } & \multicolumn{4}{|c|}{ Schooling } & \multirow[b]{3}{*}{$p$-value* } \\
\hline & 0 to 4 years & 5 to 8 years & 9 to 11 years & 12 or more & \\
\hline & Mean $( \pm$ sd $)$ & Mean $( \pm$ sd $)$ & Mean $( \pm$ sd $)$ & Mean $\left( \pm_{s d}\right)$ & \\
\hline Gender (Fem. \%) & $78.57 \%$ & $68.49 \%$ & $76.79 \%$ & $59.57 \%$ & $0.064^{*}$ \\
\hline Age & $67.55( \pm 6.29)$ & $67.47( \pm 5.16)$ & $66.04( \pm 4.86)$ & $67.11( \pm 5.68)$ & 0.502 \\
\hline Schooling & $3.76( \pm 0.80)^{\text {a.b.c }}$ & $6.89( \pm 1.14)^{\text {b.c }}$ & $10.36\left( \pm 0.82^{\mathrm{c}}\right.$ & $15.12( \pm 2.98)$ & $<0.001$ \\
\hline \multicolumn{6}{|l|}{ Length of Participation } \\
\hline UnATI EACH-USP & $2.21( \pm 2.52)$ & $2.01( \pm 2.06)$ & $1.86( \pm 1.85)$ & $2.10( \pm 2.19)$ & 0.992 \\
\hline Other U3A or Social Centers & $2.26( \pm 4.75)$ & $3.15( \pm 6.53)$ & $3.13( \pm 6.66)$ & $1.88( \pm 3.83)$ & 0.748 \\
\hline \multicolumn{6}{|c|}{ Overall Satisfaction with Life Scale } \\
\hline OSL/Total & $8.43( \pm 1.67)$ & $8.42( \pm 1.52)$ & $8.25( \pm 1.42)$ & $8.04( \pm 1.48)$ & 0.287 \\
\hline \multicolumn{6}{|c|}{ Domain Related Satisfaction Scale } \\
\hline Health & $3.77( \pm 0.75)$ & $3.92( \pm 0.58)$ & $3.77( \pm 0.80)$ & $3.71( \pm 0.67)$ & 0.436 \\
\hline Physical Capacity & $3.90( \pm 0.53)$ & $3.85( \pm 0.71)$ & $3.96( \pm 0.76)$ & $3.78( \pm 0.66)$ & 0.497 \\
\hline Mental Capacity & $3.77( \pm 0.70)$ & $3.87( \pm 0.69)$ & $3.88( \pm 0.74)$ & $4.00( \pm 0.70)$ & 0.204 \\
\hline Social Involvement & $3.99( \pm 0.63)$ & $3.89( \pm 0.86)$ & $3.84( \pm 0.99)$ & $3.85( \pm 0.68)$ & 0.697 \\
\hline DRS/ Total & $3.86( \pm 0.46)$ & $3.90( \pm 0.51)$ & $3.88( \pm 0.67)$ & $3.84( \pm 0.47)$ & 0.931 \\
\hline \multicolumn{6}{|l|}{ Affect Schedule } \\
\hline Positive (PA) & $3.74( \pm 0.55)$ & $3.79( \pm 0.61)$ & $3.82( \pm 0.55)$ & $3.82( \pm 0.56)$ & 0.884 \\
\hline Negative (NA) & $1.73( \pm 0.64)$ & $1.66( \pm 0.72)$ & $1.73( \pm 0.65)$ & $1.84( \pm 0.70)$ & 0.189 \\
\hline A/Total & $4.06( \pm 0.49)$ & $4.11( \pm 0.60)$ & $4.08( \pm 0.56)$ & $4.02( \pm 0.58)$ & 0.546 \\
\hline
\end{tabular}


Continued from Table 3

\begin{tabular}{lccccc}
\hline & \multicolumn{5}{c}{ Schooling } \\
Variable & 0 to 4 years & 5 to 8 years & 9 to 11 years & 12 or more \\
& Mean $( \pm$ sd $)$ & Mean $( \pm$ sd $)$ & Mean $( \pm$ sd $)$ & Mean $( \pm$ sd $)$ & $p$-value* \\
\hline Personal Development Scale & & & & & \\
Factor 1 & $4.22( \pm 0.46)$ & $4.22( \pm 0.44)$ & $4.23( \pm 0.42)$ & $4.30( \pm 0.47)$ & 0.411 \\
Factor 2 & $3.59( \pm 0.71)$ & $3.53( \pm 0.74)$ & $3.72( \pm 0.65)$ & $3.70( \pm 0.69)$ & 0.416 \\
Factor 3 & $3.89( \pm 0.60)$ & $3.90( \pm 0.66)$ & $3.94( \pm 0.49)$ & $4.05( \pm 0.60$ & 0.234 \\
Factor 4 & $3.68( \pm 0.79)$ & $3.65( \pm 1.02)$ & $3.69( \pm 0.96)$ & $3.90( \pm 0.79)$ & 0.322 \\
Factor 5 & $3.91( \pm 0.84)$ & $3.91( \pm 0.81)$ & $3.86( \pm 0.76)$ & $4.02( \pm 0.73)$ & 0.719 \\
PDS/Total & $3.97( \pm 0.39)$ & $3.97( \pm 0.41)$ & $4.01( \pm 0.38)$ & $4.10( \pm 0.41)$ & 0.069 \\
\hline
\end{tabular}

${ }^{*} p$-value related to chi-square test. $p$-value related to Kruskal-Wallis test, followed by Multiple Comparisons z' values test: a. differs from 5 to 8 years; b. differs from 9 to 11 years; c. differs from 12 years or more; Factor 1: Self-realization, Personal Growth and Psychological Adjustment; Factor 2: Productivity; Factor 3: Care; Factor 4: Concern for next generations; Factor 5: Commitment to others.

Table 4. Sociodemographic variables and well-being among elderly persons stratified by time of participation. São Paulo, UnATI EACH, 2010.

\begin{tabular}{|c|c|c|c|c|c|}
\hline \multirow{3}{*}{ Variable } & \multicolumn{4}{|c|}{ Time of Participation at UnATI EACH-USP } & \multirow[b]{3}{*}{$p$-value* } \\
\hline & Freshman & 1 Semester. & 1 Year & $>1$ Year & \\
\hline & Mean $( \pm s d)$ & Mean $( \pm$ sd $)$ & Mean $( \pm$ sd) & Mean $( \pm$ sd) & \\
\hline Gender (Fem. \%) & $65.43 \%$ & $72.22 \%$ & $62.79 \%$ & $72.41 \%$ & $0.579 *$ \\
\hline Age & $66.69( \pm 5.76)$ & $66.76( \pm 5.37)$ & $67.12( \pm 5.32)$ & $67.53( \pm 5.40)$ & 0.618 \\
\hline Schooling & $10.19( \pm 4.99)$ & $10.06( \pm 4.47)$ & $9.72( \pm 4.81)$ & $10.14( \pm 4.54)$ & 0.953 \\
\hline \multicolumn{6}{|l|}{ Length of Participation } \\
\hline UnATI EACH-USP & $0.00( \pm 0.00)$ & $1.00( \pm 0.00)$ & $2.00( \pm 0.00)$ & $4.61( \pm 1.65)$ & $<0.001^{* *}$ \\
\hline Other U3A or Social Centers & $1.73( \pm 4.73)$ & $2.52( \pm 4.73)$ & $3.37( \pm 6.55)$ & $2.94( \pm 5.92)$ & 0.209 \\
\hline \multicolumn{6}{|c|}{ Overall Satisfaction with Life Scale } \\
\hline OSL/Total & $8.11( \pm 1.57)$ & $8.39( \pm 1.37)$ & $8.38( \pm 1.41)$ & $8.24( \pm 1.59)$ & 0.717 \\
\hline \multicolumn{6}{|c|}{ Domain Related Satisfaction Scale } \\
\hline Health & $3.74( \pm 0.79)$ & $3.80( \pm 0.74)$ & $3.79( \pm 0.63)$ & $3.84( \pm 0.60)$ & 0.819 \\
\hline Physical Capacity & $3.82( \pm 0.71)$ & $3.92( \pm 0.69)$ & $3.94( \pm 0.65)$ & $3.81( \pm 0.66)$ & 0.635 \\
\hline Mental Capacity & $3.91( \pm 0.79)$ & $3.92( \pm 0.69)$ & $3.90( \pm 0.76)$ & $3.89( \pm 0.63)$ & 0.964 \\
\hline Social Involvement & $3.77( \pm 0.90)$ & $4.00( \pm 0.81)$ & $3.96( \pm 0.67)$ & $3.87( \pm 0.74)$ & 0.330 \\
\hline DRS/ Total & $3.83( \pm 0.62)$ & $3.92( \pm 0.53)$ & $3.91( \pm 0.49)$ & $3.86( \pm 0.45)$ & 0.675 \\
\hline \multicolumn{6}{|l|}{ Affect Schedule } \\
\hline Positive (PA) & $3.73( \pm 0.62)$ & $3.87( \pm 0.55)$ & $3.80( \pm 0.55)$ & $3.82( \pm 0.54)$ & 0.459 \\
\hline Negative (NA) & $1.83( \pm 0.67)$ & $1.62( \pm 0.61)$ & $1.70( \pm 0.69)$ & $1.77( \pm 0.74)$ & 0.237 \\
\hline A/Total & $3.99( \pm 0.57)$ & $4.16( \pm 0.51)$ & $4.10( \pm 0.57)$ & $4.06( \pm 0.59)$ & 0.164 \\
\hline \multicolumn{6}{|l|}{ Personal Development Scale } \\
\hline Factor 1 & $4.21( \pm 0.46)$ & $4.26( \pm 0.44)$ & $4.33( \pm 0.44)$ & $4.24( \pm 0.44)$ & 0.521 \\
\hline Factor 2 & $3.51( \pm 0.69)$ & $3.68( \pm 0.74)$ & $3.76( \pm 0.66)$ & $3.67( \pm 0.70)$ & 0.153 \\
\hline Factor 3 & $3.97( \pm 0.58)$ & $4.09( \pm 0.57)$ & $3.93( \pm 0.68)$ & $3.89( \pm 0.58)$ & 0.223 \\
\hline Factor 4 & $3.92( \pm 0.93)$ & $3.65( \pm 0.86)$ & $3.72( \pm 0.87)$ & $3.67( \pm 0.90)$ & 0.175 \\
\hline Factor 5 & $3.97( \pm 0.84)$ & $3.99( \pm 0.80)$ & $3.96( \pm 0.84)$ & $3.86( \pm 0.75)$ & 0.634 \\
\hline PDS/Total & $4.01( \pm 0.41)$ & $4.02( \pm 0.40)$ & $4.08( \pm 0.40)$ & $4.00( \pm 0.40)$ & 0.691 \\
\hline
\end{tabular}

${ }^{*} p$-value related to chi-square test. ${ }^{*} p$-value related to Kruskal-Wallis test; Factor 1: Self-realization, Personal Growth and Psychological Adjustment; Factor 2: Productivity; Factor 3: Care; Factor 4: Concern for future generations; Factor 5: Commitment to others. 
Table 5. Sociodemographic variables and well-being among elderly persons stratified by length of time spent in the program, first-years or veterans. São Paulo, UnATI EACH, 2010.

\begin{tabular}{|c|c|c|c|}
\hline \multirow{3}{*}{ Variable } & \multicolumn{2}{|c|}{ Group } & \multirow[b]{3}{*}{$p$-value* } \\
\hline & First-years & Veterans & \\
\hline & Mean $( \pm$ sd $)$ & Mean $(\underline{ \pm d})$ & \\
\hline Gender (Fem. \%) & $65.43 \%$ & $70.11 \%$ & $0.449 *$ \\
\hline Age & $66.69( \pm 5.76)$ & $67.21( \pm 5.35)$ & 0.320 \\
\hline Schooling & $10.19( \pm 4.99)$ & $10.02( \pm 4.56)$ & 0.933 \\
\hline \multicolumn{4}{|l|}{ Length of Participation } \\
\hline UnATI EACH-USP & $0.00( \pm 0.00)$ & $2.94( \pm 1.98)$ & $<0.001 * *$ \\
\hline Other U3A or Social Centers & $1.73( \pm 4.73)$ & $2.92( \pm 5.73)$ & $0.035^{* *}$ \\
\hline \multicolumn{4}{|c|}{ Overall Satisfaction with Life Scale } \\
\hline OSL/Total & $8.11( \pm 1.57)$ & $8.32( \pm 1.48)$ & 0.284 \\
\hline \multicolumn{4}{|c|}{ Domain Related Satisfaction Scale } \\
\hline Health & $3.74( \pm 0.79)$ & $3.81( \pm 0.65)$ & 0.473 \\
\hline Physical Capacity & $3.82( \pm 0.71)$ & $3.87( \pm 0.67)$ & 0.748 \\
\hline Mental Capacity & $3.91( \pm 0.79)$ & $3.90( \pm 0.67)$ & 0.913 \\
\hline Social Involvement & $3.77( \pm 0.90)$ & $3.93( \pm 0.74)$ & 0.196 \\
\hline DRS/Total & $3.83( \pm 0.62)$ & $3.89( \pm 0.48)$ & 0.356 \\
\hline \multicolumn{4}{|l|}{ Affect Schedule } \\
\hline Positive (PA) & $3.73( \pm 0.62)$ & $3.83( \pm 0.54)$ & 0.142 \\
\hline Negative (NA) & $1.83( \pm 0.67)$ & $1.71( \pm 0.69)$ & 0.092 \\
\hline A/Total & $3.99(0 \pm .57)$ & $4.10( \pm 0.56)$ & $0.050^{* *}$ \\
\hline \multicolumn{4}{|l|}{ Personal Development Scale } \\
\hline Factor 1 & $4.21( \pm 0.46)$ & $4.27( \pm 0.44)$ & 0.398 \\
\hline Factor 2 & $3.51( \pm 0.69)$ & $3.70( \pm 0.70)$ & $0.028^{* *}$ \\
\hline Factor 3 & $3.97( \pm 0.58)$ & $3.96( \pm 0.60)$ & 0.729 \\
\hline Factor 4 & $3.92( \pm 0.93)$ & $3.68( \pm 0.88)$ & $0.030 * *$ \\
\hline Factor 5 & $3.97( \pm 0.75)$ & $3.92( \pm 0.79)$ & 0.737 \\
\hline PDS/Total & $4.01( \pm 0.41)$ & $4.03( \pm 0.40)$ & 0.810 \\
\hline
\end{tabular}

${ }^{*} p$-value related to chi-squared test. ${ }^{* *} p$-value related to Mann-Whitney U-Test; Factor 1: Self-realization, Personal Growth and Psychological Adjustment; Factor 2: Productivity; Factor 3: Care; Factor 4: Concern for future generations; Factor 5: Commitment to others.

\section{DISCUSSION}

The analysis of the results of the sample of 265 students of UnATI EACH suggests that men are more satisfied and happy than women. Yang ${ }^{13}$, Plagnol and Easterlin ${ }^{14}$, in studies carried out in the USA and in another 65 countries, found that men are happier than women after middle age. In the study by Hansen and Slagsvold ${ }^{15}$, the authors found that in a sample of 3,750 people aged between 40 and 85 , both men and women presented similar patterns of overall satisfaction with their lives, even though women are more likely to be widows and caregivers of spouses than men.

Neri et al. ${ }^{9}$ also confirmed the findings of the present study. According to the authors, the SWB and self-concept of elderly women are more negative than those of men. The reasons for these data are wellknown: women are more ill, dependent, alone, poor and suffer more medical complaints than men, and have lower expectations; they tend to be considered less attractive and less valued than men. 
In relation to the positive results obtained by men in terms of satisfaction with health, personal mental capacity and when compared to other people of the same age, Sposito et al. ${ }^{16}$ found in a study with 125 elderly persons that men are more satisfied with their health in comparison with other individuals of the same age. The same finding occurred in relation to the evaluation of mental capacity. A study by LimaSilva et al. ${ }^{17}$ based on a sample of 383 elderly residents of the neighborhood of Ermelino Matarazzo in the municipal region of São Paulo, found that men exhibited a greater cognitive performance than women, perhaps due to higher schooling. The opposite was identified in a study with a sample of elderly Europeans. In this study, the cognitive performance of women was better than that of men, a finding justified by the increase in educational levels in the last four decades in the European continent ${ }^{18}$. The data presented may suggest that satisfaction with the mental ability domain may be influenced by socioeconomic factors, which can result in higher cognitive performance.

The results related to age and the SWB indicators of this study are in keeping with data in literature. In the first study identified in non-Brazilian literature on the relationship between age and life satisfaction, Campbell et al. ${ }^{19}$ found similar data to the findings of the research at UnATI EACH. The authors identified that older people, when compared to younger groups, were more satisfied and happy with life.

For Diener and Suh ${ }^{20}$, the elderly have a lower aspirational level than younger people because they are more prepared, or in other words, they have been taught not to expect so much from life. Older people adjust their goals to their resources and competencies and thus have lower expectations of achievement and pleasure than younger people, and so their assessments of life are more positive. This conclusion exemplifies the role of the self in regulating individual functioning and in determining the sense of SWB in old age.

Authors such as Yang ${ }^{13}$, Charles and Carstensen ${ }^{21}$ and Sposito et al. ${ }^{22}$ affirm that SWB does not decline with age, a fact verified in the present study. In the studies of these researchers all the findings indicated a greater satisfaction with life among elderly persons and reported that advanced age is related to an increase in the capacity to regulate the emotions and the expression of more positive affections and lower levels of negative affections.

Elderly persons aged over 65 years presented high SWB measurements. These data suggest that this group may be more adapted to the loss of their family and social roles than younger elderly persons (60-64).

These results are also consistent with the Lifespan Perspective in Psychology, described by Baltes and Carstensen $^{23}$. The authors speak of increasing wisdom and emotional intelligence with the advancement of age and state that the reduction in negative affective states is a result of increasing wisdom. The findings are congruent with the Socioemotional Selectivity Theory of English and Carstensen ${ }^{11}$, where elderly persons have a greater ability to self-regulate emotions and see situations more positively.

In relation to the data obtained in the domains of comparisons of satisfaction with health, physical and mental capacity with people of the same age, Sposito et al. ${ }^{16}$ found positive results among older elderly people resident in the city of Campinas, based on the same scale used in the UnATI EACH study.

Cheng et al. ${ }^{24}$ conducted two studies to evaluate age differences through social comparison and their effect on health self-assessment. The two studies aimed to shed light on the theme of social comparison as a mechanism that can help older adults maintain their self-rated health in the face of physical decline. Study 1 examined whether selfrated health was related to a more positive physical self-perception in comparison with others and whether such relationships differed according to age. Study 2 focused on older adults, where over a twelve-month period it was verified through social comparison whether increases in physical symptoms were associated with greater self-improvement in the physical domain. In study 1 , it was observed that the effect of social comparison is greater for the elderly than for younger people. The positive effect of social comparison on the self-assessment of health was verified. Study 2 found that elderly persons who perceive their physical mastery to be better than others are more likely to maintain their selfrated health when faced with an increase in physical symptoms. In summary, the authors concluded that social comparison plays a more important role in 
determining self-assessment of health (study 1) and in fact is effective in partially compensating for the negative effect of the increasing physical symptoms that accompany aging (study 2).

Schooling is described in literature as a strong determinant of SWB, especially among young and middle-aged people ${ }^{25}$. This data explains the lack of significant results for this variable in the present study, as the sample was comprised of elderly people. The fact that men had higher levels of schooling $(M=10.88)$ did not reflect the overall satisfaction with life score.

Similar data were verified by Yang ${ }^{13}$. The author states that schooling is strongly related to happiness at all ages except among the elderly. In a systematic review conducted by Read et al. ${ }^{26}$, the data revealed that income is more strongly associated with wellbeing than education. In this review, education was more associated with self-perception of health than with the evaluation of satisfaction with life.

It can be concluded that both schooling and opportunities for education in general offer important attributes for an individual to participate in activities to acquire knowledge and form social connections, which are linked to SWB, but which are not predictors of SWB, especially for the sample of this study.

To evaluate the effect of the time of participation in the activities of the UnATI EACH on the SWB and PWB of the students, participants were characterized as First-years: beginners in the program (first semester of 2010) and Veterans: those with a participation time equal to or greater than one semester. The group of veteran students were more emotionally positive than the first-years, since they had high rates of positive affect. They were also happier and less demotivated than the first-years, and described a desire to be productive, while the first-years were more concerned about the next generations.

The positive emotional well-being reported by veterans suggests that UnATI EACH provides significant social and educational situations. They are happy with the network of social relations established and motivated to learn. This conclusion is confirmed by authors such as Charles and Carstensen ${ }^{21}$ who assert that elderly persons tend to maintain the maximum number of positive experiences with their networks of social relationships, avoiding situations or people who result in negative feelings.

It can also be emphasized that regular social contacts, such as those provided by UnATI EACH, act as emotional support to participants. The findings of a study by Matz-Costa et al. ${ }^{27}$ point to the benefits of continuing education as an informational and instrumental source for the needs of the elderly. It acts as an important stimulus for interpersonal relations and the acquisition of new knowledge.

The sense of productivity described by veteran students expresses commitment to the people closest to them and their own contribution to society. This contribution is translated in literature as the desire to guide and teach and, consequently, to be part of the memory of the group. Similar data were verified by Queroz ${ }^{28}$ in surveys which analyzed the PWB of middle-aged and elderly people through the Personal Development Scale. According to the author, positive self-reports about psychological adjustment predominated among the elderly, who expressed their concerns and goals as geared towards specific individuals and groups.

Associations were made between the time and the characteristics of participation in the UnATI EACH and in other U3A or Social Centers. From this association, three groups were generated: Group I (first-years in all programs), Group II (first-years from UnATI EACH, but participants for a semester or more in other institutions of this type, and veterans of UnATI EACH who had never participated in other programs) and Group III (veterans in all programs with a time of participation of one semester or more).

Although a causal relationship was not established, a participation time of over six months in UnATI $\mathrm{EACH}$ and other U3A and Social Centers seemed to be a determining factor for positive SWB and PWB indices in the sample studied. In agreement with the results obtained in the current study, researchers such as Ordonez et al. ${ }^{29}$ described the positive impact that participation in permanent education programs provides to the elderly, in relation to physical and mental health, social relations, a positive affective state, and satisfaction with life. 
Regarding the sense of psychological adjustment, factors of the Personal Development Scale (productivity, care and concern for the next generations) are related to generative concerns, and for Erikson ${ }^{30}$ generability is an important component of the development of adulthood. These factors would be more directed toward interpersonal psychological the exercise of adult roles, in the family, at work, in the community, in social institutions and in society in general. According to Erikson, ${ }^{30}$ generability is an indicator of adjustment: generative actions manifest themselves from adulthood through care and commitment to caring for people (procreation), dedicating time and energy to one's productive life (productivity) and ideas (creativity) through which the individual learns to care about themselves. The fulfillment of these tasks is socially valued. According to McAdams ${ }^{31}$, generative concern is positively associated with PWB measures and personality traits - extroversion, affability, openness to experiences and emotional stability, and low tendency to neurosis.

It is important to note some limitations of the present study. The most important of these is that the sample is not representative of the Brazilian elderly population, since the average level of schooling is higher. In theory, it can be said that it is representative of the population attending educational programs for the elderly. It may also be considered a limitation that students already have the characteristics of a successful and active aging, since they have successfully enrolled in the programs.

Additionally, the impact of the intensity of participation in the activities (number of workshops and frequency) was not investigated.

\section{REFERENCES}

1. Da Silva HS, De Lima AMM, Galhardoni R. Envelhecimento bem-sucedido e vulnerabilidade em saúde: aproximações e perspectivas. Intervace. 2014:1-11.

2. Ryff CD. Happiness is everything, or is it? Explorations on the meaning of psychological wellbeing. J Pers Soc Psychol. 1989;57(6):1069-81.

3. Neri LA. Fragilidade e qualidade de vida na velhice. Campinas: Alínea. 2013. p.16-29.

\section{CONCLUSION}

It can be concluded that the Open University for the Third Age of the School of Arts, Sciences and Humanity has supported the desire to establish important and memorable connections with others. Elderly persons want the program to provide them with knowledge that can generate meaningful actions and leave a personal legacy.

It was concluded, then, that permanent education for the elderly, provided by universities and through other sources, contributes to maintaining high rates of satisfaction with life and positive feelings. Older people can assess their own development trajectory and commitment to society, and consider their own commitment to pursuing an ideal of personal excellence. It can be said that living through the experience of aging as a privileged moment of life is also something that is learned in an educational establishment.

It is important to note that the empirical work carried out so far has been cross-sectional. Future research should examine the action of time and the associations of subjective and psychological wellbeing in UnATI students longitudinally.

A strength of this study is that it is pioneering in Brazilian literature. In terms of both the representative number of elderly people from an Open University of the Third Age surveyed and the subject investigated, there are no other studies that have used instruments for the joint evaluation of the two constructs - subjective and psychological well-being - and verified their possible correlations.

4. Diener E, Tay L. Subjective well-being and human welfare around the world as reflected in the Gallup World Poll. Int J Psychol. 2015;50(2):135-49.

5. Diener E. The remarkable changes in the science of subjective well-being. Perspect Psychol Sci. 2013;8(6):663-6.

6. Ryff CD. Psychological well-being revisited: Advances in the science and practice of eudaimonia. Psychother Psychosom. 2013;83(1):10-28. 
7. Lawton MP. A multidimensional view of quality of life in frail elders. The concept and measurement of quality of life in the frail elderly. In: Birren JE, Lubben JE, Rowe JC, Deufchman DE. The Concept and measurement of quality of life in the frail elderly. Amsterdam: Elsevier; 1991. p. 4-27.

8. Steptoe A, Deaton A, Stone AA. Subjective wellbeing, health, and ageing. Lancet. 2015;385(9968):640-8.

9. Neri AL, Batistoni SST, Ribeiro CC. Bem-estar psicológico, saúde e longevidade. In: Freitas EV, Py L, editores. Tratado de Geriatra e Gerontologia. $4^{\mathrm{a}}$ ed. Rio de Janeiro: Guanabara-Koogan; 2016. p.1458-67.

10. Jivraj S, Nazroo J, Vanhoutte B, Chandola T. Aging and subjective well-being in later life. J Gerontol Ser B Psychol Sci Soc Sci. 2014;69(6):930-41.

11. English T, Carstensen LL. Socioemotional selectivity theory. In: Pachana AN, editor. Encyclopedia of Geropsychology. Singapore: Springer Singapore; 2015. p. 1-6.

12. Mackowicz J, Wnek-Gozdek J. “It's never too late to learn"-How does the Polish U3A change the quality of life for seniors? Educ Gerontol. 2016;42(3):186-97.

13. Yang Y. Social inequalities in happiness in the United States, 1972 to 2004: an age-period-cohort analysis. Am Socioll Rev. 2008;73(2):204-26.

14. Plagnol AC, Easterlin RA. Aspirations, attainments, and satisfaction: Life cycle differences between American women and men. J Happiness Stud. 2008;9(4):601-19.

15. Hansen T, Slagsvold B. The age and subjective well-being paradox revisited: a multidimensional perspective. Norsk epidemiol. 2012;22(2):187-92.

16. Sposito G, Diogo MJDE, Cintra FA, Neri AL, Guariento ME, Sousa MLR. Relações entre bem-estar subjetivo e mobilidade e independência funcional por função de grupo de faixas etárias e de gêneros em idosos. Acta fisiátrica. 2010;17(3)103-8.

17. Da Silva TBL, De Oliveira ACV, Paulo DLV, Malagutti MP, Danzini VMP, Yassuda MS. Treino cognitivo para idosos baseado em estratégias de categorização e cálculos semelhantes a tarefas do cotidiano. Rev Bras Geriatr Gerontol. 2011;14(1):65-74.

18. Weber D, Skirbekk V, Freund I, Herlitz A. The changing face of cognitive gender differences in Europe. Proc Natl Acad Sci U.S.A. 2014;111(32):11673-8.
19. Campbell A, Converse PE, Rodgers WL. The quality of American life: Perceptions, evaluations, and satisfactions. New York: Russell Sage Foundation; 1976.

20. Diener E, Suh E. Measuring quality of life: economic, social, and subjective indicators. Soc Indicators Res. 1997;40(1-2):189-216.

21. Charles S, Carstensen LL. Social and emotional aging. Ann Rev Psychol. 2010;61:383.

22. Sposito G, D'Elboux MJ, Neri AL, Guariento ME. A satisfação com a vida e a funcionalidade em idosos atendidos em um ambulatório de geriatria. Ciênc Saúde Coletiva. 2013;18(12):3475-82.

23. Baltes MM, Carstensen LL. The process of successful aging: Selection, optimization, and compensation. In: Staudinger UM, Lindenberger U. Understanding human development: [ place unknown]: Springer; 2003:81-104.

24. Cheng ST, Fung H, Chan A. Maintaining self-rated health through social comparison in old age. J Gerontol Ser B Psychol Sci Soc Sci. 2007;62(5):277-85.

25. George LK. Still happy after all these years: research frontiers on subjective well-being in later life. J Gerontol Ser B Psychol Sci Soc Sci. 2010;65(3):331-9.

26. Read S, Grundy E, Foverskov E. Socio-economic position and subjective health and well-being among older people in Europe: a systematic narrative review. Aging Ment Health. 2016;20(5):529-42.

27. Matz-Costa C, Besen E, James JB, Pitt-Catsouphes M. Differential impact of multiple levels of productive activity engagement on psychological well-being in middle and later life. Gerontologist. 2014;54(2):277-89.

28. Queroz NC. Bem-estar psicologico: investigações acerca de recursos adaptativos em adultos e na meiaidade [tese]. Campinas: Universidade Estadual de Campinas; 2008.

29. Ordonez TN, Batistoni SST, Cachioni M. Síntomas depresivos en adultos mayores participantes de una universidad abierta a la tercera edad. Rev Esp Geriatr Gerontol. 2011;46(5):250-5.

30. Erikson EH. O ciclo de vida completo. Porto Alegre: ARTMED; 1998.

31. McAdams DP. The positive psychology of adult generativity: Caring for the next generation and constructing a redemptive life. Positive Psychology: Springer; 2013:191-205. 